\title{
TEMPORAL LOBE HYPOGENESIS ASSOCIATED WITH ARACHNOID CYST IN PATIENTS WITH EPILEPSY
}

\author{
Eliane Kobayashi, Leonardo Bonilha, Li M. Li, Fernando Cendes
}

\begin{abstract}
Objective: To determine the frequency of temporal lobe hypogenesis (TLH) associated with arachnoid cysts (AC) in patients with epilepsy. Method: We retrospectively revised 655 consecutive MRI scans from patients followed in our epilepsy clinic. We identified patients with temporal AC and then performed careful visual analysis in a workstation. Patients with evident expansive or destructive lesions were excluded. Results: Only $4(0.6 \%)$ patients had AC in the left temporal lobe, all associated with TLH. In addition, there were also ipsilateral dysgenetic characteristics in the ipsilateral hippocampus including abnormal shape and axis, and hyperintense T2 signal. In one patient this hippocampal abnormality was bilateral. Conclusion: AC with TLH was rarely found in our patients with epilepsy and it was always associated with hippocampal dysgenesis. Although volumetric reduction of the temporal lobe can be observed in patients with epilepsy and hippocampal abnormalities, the presence of adjacent AC points to a malformative etiology.
\end{abstract}

KEY WORDS: hippocampal dysgenesis, cortical development malformation, partial epilepsy, seizures, magnetic resonance imaging.

\begin{abstract}
Hipogenesia de lobo temporal associada a cisto aracnóide em pacientes com epilepsia
RESUMO - Objetivo: Determinar a freqüência de hipogenesia de lobo temporal (HLT) associada a cistos de aracnóide (CA) em pacientes com epilepsia. Método: Revisamos retrospectivamente 655 exames consecutivos de ressonância magnética de pacientes do ambulatório de epilepsia da UNICAMP. Identificamos os pacientes com CA na região temporal e então realizamos análise visual em uma estação de trabalho. Pacientes com lesões expansivas ou destrutivas evidentes foram excluídos. Resultados: Apenas 4 (0,6\%) pacientes tinham CA na região temporal esquerda, todos associados a HLT. Além destas alterações, observamos características disgenéticas no hipocampo ipsilateral incluindo anormalidades no formato e eixo e hipersinal em T2. Em um paciente estas alterações hipocampais eram bilaterais. Conclusão: CAs associados a HLT foram raramente encontrados, e quando presentes, estavam sempre acompanhados de disgenesia hipocampal. Apesar da redução volumétrica do lobo temporal poder ser observada em pacientes com epilepsia e alterações hipocampais, a presença de um CA adjacente indica uma etiologia de malformação.
\end{abstract}

PALAVRAS-CHAVE: disgenesia hipocampal, epilepsia parcial, convulsões, cistos de aracnóide, ressonância magnética.

Arachnoid cysts are considered frequent and incidental findings in neuroimaging studies'. The most frequent localization is in the middle fossa, corresponding to more than half the cases reported in the literature ${ }^{2}$. The origin of middle fossa arachnoid cysts is related to two theories: primary malformation of arachnoid (Starkman et al. $)^{3}$ or secondary development due to partial agenesis of the temporal lobe (Robinson et al.) ${ }^{4}$. Magnetic Resonance Imaging (MRI) demonstrated the presence of morphologic abnormalities in the temporal lobe and adjacent bone remodeling, which indicate a secondary origin of arachnoid cysts ${ }^{1}$. Temporal lobe agenesis/hypogene- sis is believed to be an important etiology of middle fossa arachnoid cysts ${ }^{4,5}$.

The temporal region is quite important in epileptology, since temporal lobe epilepsy (TLE) is not only the most frequent form of epilepsy in adults, but also the refractory epilepsy with the best post-operative results ${ }^{4}$. In TLE the main feature is the hippocampal atrophy $(\mathrm{HA})$, which can be associated with atrophy of the amygdala and the temporal lobe ${ }^{5}$. In HA we observe reduced hippocampal volume, with abnormal internal structure, which causes an abnormally flat shape and altered internal signal (hyperintense T2 and hypointense T1 signal). Studies on rela-

Department of Neurology, Faculdade de Ciências Médicas (FCM), Campinas State University (UNICAMP), Campinas SP, Brazil. This study was supported by FAPESP, São Paulo, Brazil.

Received 26 September 2002. Accepted 5 December 2002.

Dr. Fernando Cendes - Departamento de Neurologia, FCM - UNICAMP - Caixa Postal 6111 - 13083-970 Campinas SP - Brasil. FAX: 5519 32891818.E-mail: fcendes@unicamp.br 


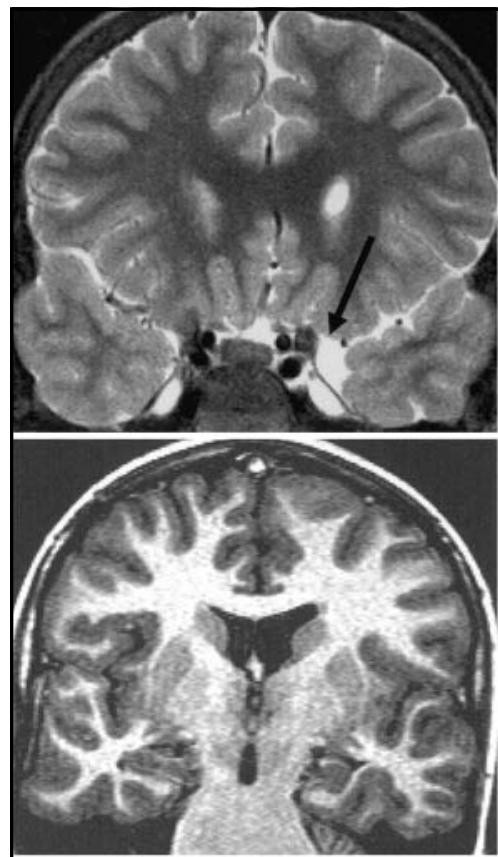

Patient 1

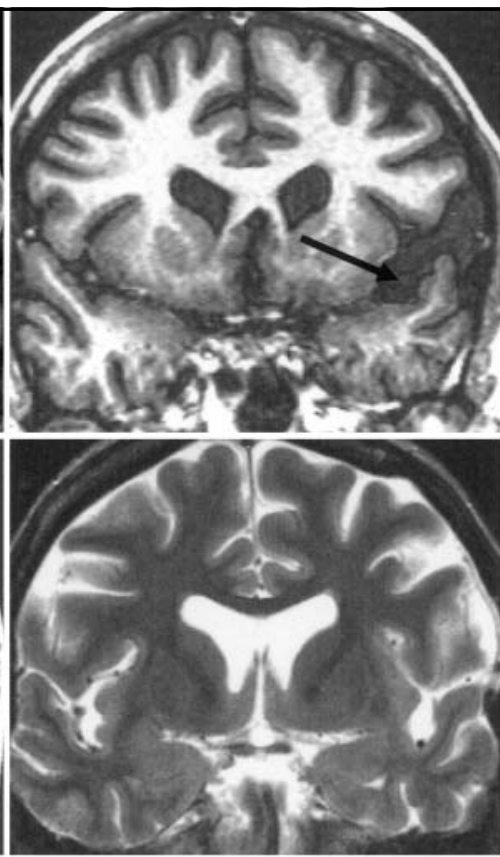

Patient 2

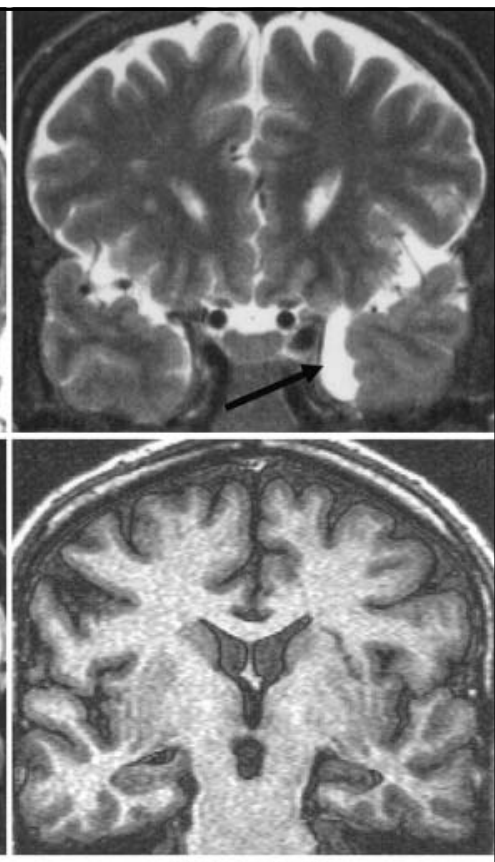

Patient 3

Fig 1. T1-IR and T2 weighted coronal images from patients 1, 2 and 3 with left temporal lobe hypogenesis associated with arachnoid cysts (arrows).

tionship between cysts and seizure foci, however, have proved negative $e^{6,7}$.

The objective of this study is to determine the prevalence of temporal lobe hypogenesis associated with middle fossa arachnoid cysts in our patients with epilepsy.

\section{METHOD}

We retrospectively revised 655 consecutive MRIs from patients with epilepsy from UNICAMP Clinical Hospital. MRIs were acquired in a 2Tesla scanner (Elscint Prestige ${ }^{\circledR}$ ), and kept in optical disk for revision in a workstation $\left(\mathrm{OMNIPRO}^{\circledR}\right)$. Exclusion criteria were evident destructive or expansive abnormalities identified in MRI.

Acquisition parameters were: (1) Sagital T1 spin echo, $6 \mathrm{~mm}$ thick, flip angle $=180^{\circ}$; repetition time $(T R)=430$, echo time $(T E)=12$, matrix $200 \times 350$, field of view $(F O V)=$ $25 \times 25 \mathrm{~cm}$; (2) Coronal images, perpendicular to long axis of hippocampus, defined on the sagital images: (a) T2- weighted and proton density "fast spin echo" (FSE), $3 \mathrm{~mm}$ thick, flip angle $=160^{\circ} ; \mathrm{TR}=4800, \mathrm{TE}=108 / 18$, matrix 256X256, FOV $=22 \times 22 \mathrm{~cm}$; (b) T1-weighted inversion recovery (IR), $3 \mathrm{~mm}$ thick, flip angle $=200^{\circ}$; $\mathrm{TR}=2800$, $\mathrm{TE}=14$, inversion time $(\mathrm{TI})=840$, matrix $130 \times 256$, $\mathrm{FOV}=16 \mathrm{X} 18 \mathrm{~cm}$; (3) Axial images parallel to the long axis of the hippocampi: (a) T1-weighted gradient echo, $3 \mathrm{~mm}$ thick, flip angle $=70^{\circ}, \mathrm{TR}=200, \mathrm{TE}=5$, matrix $180 \times 232$, $\mathrm{FOV}=22 \times 22 \mathrm{~cm}$; (b) T2-weighted FSE, 4mm thick, flip angle $=120^{\circ}, \mathrm{TR}=6800, \mathrm{TE}=129$, matrix $252 \times 328$, $\mathrm{FOV}=21 \mathrm{X} 23 \mathrm{~cm}$; (4) T1-weighted 3D gradient echo with $1 \mathrm{~mm}$ isotropic voxel, acquired in the sagital plane for multiplanar reconstruction $\left(1 \mathrm{~mm}\right.$ thick, flip angle $=35^{\circ}$; $\mathrm{TR}=22, \mathrm{TE}=9$, matrix $256 \times 220, \mathrm{FOV}=23 \times 25 \mathrm{~cm}$ ).

\section{RESULTS}

Only 4/655 (0.6\%) from evaluated scans presented middle fossa arachnoid cysts, all in the left side and associated with signs of temporal lobe hypo-

Table 1. Data from the four patients with middle fossa arachnoid cysts.

\begin{tabular}{cclll}
\hline Patient & Sex, Age (years) & Epilepsy syndrome & Outcome & EEG \\
\hline 1 & M, 13 & Simple febrile seizure & good & Left temporal slow waves \\
2 & F, 38 & Mesial TLE & poor & Bitemporal epileptiform discharges \\
3 & M, 53 & GTCSsleep & good & Left temporal epileptiform discharges \\
4 & F, 39 & GTCSsleep & good & Not available \\
\hline
\end{tabular}

TLE, temporal lobe epilepsy; GTCSsleep, generalized tonic-clonic seizures during sleep. 

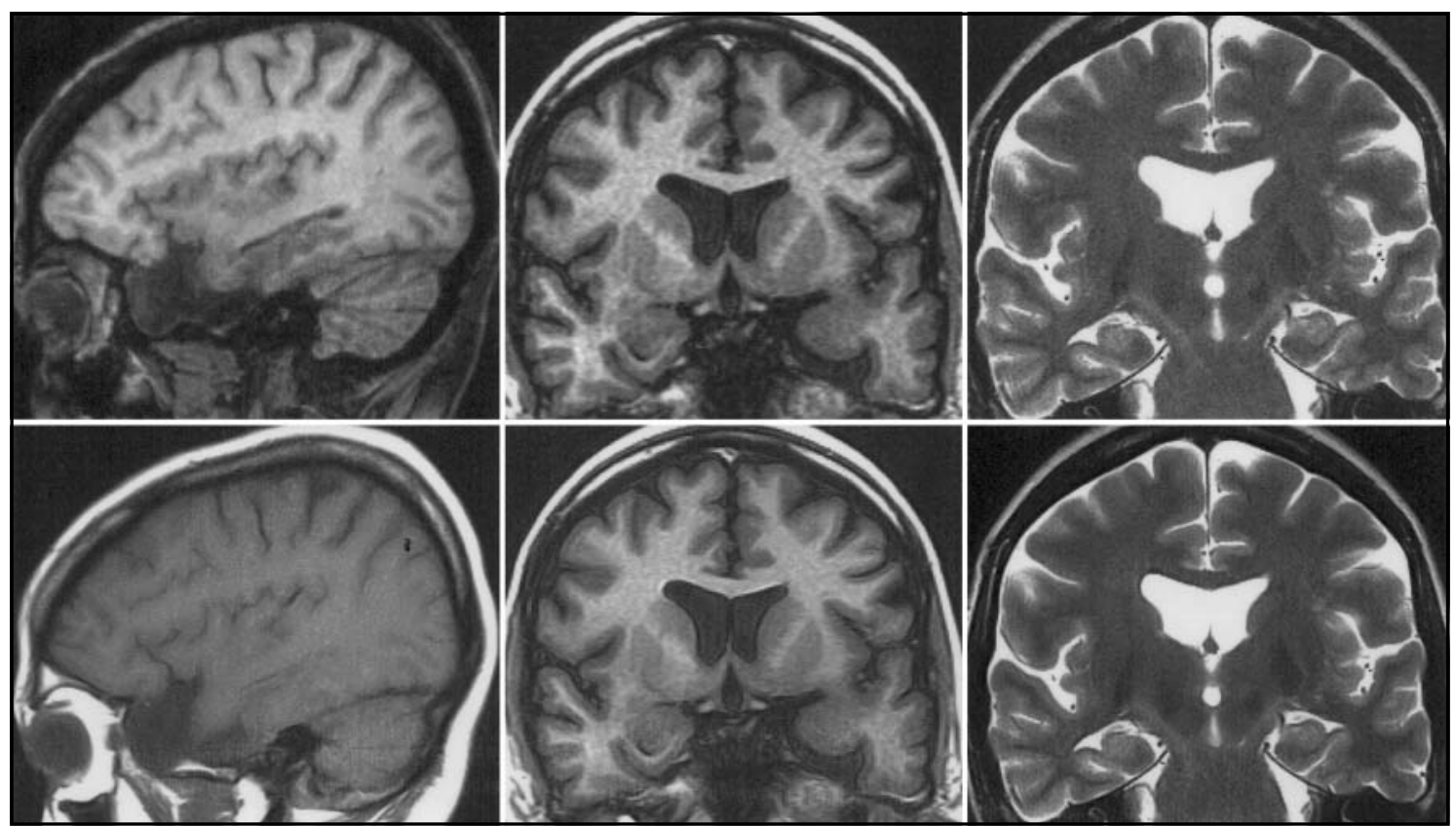

Fig 2. Images from patient 4 show left temporal lobe hypogenesis associated with arachnoid cyst, bilateral hippocampal abnormalities (rounded shape, vertical axis) and deep collateral sulcus.

genesis (Fig 1). A summary of patients characteristics is shown in Table 1.

Ipsilateral hippocampus had dysgenetic characteristics in all of them, with rounded shape, vertical axis and hyperintense $\mathrm{T} 2$ signal. In one patient this hippocampal abnormality was observed also in the contralateral hippocampus (Fig 2). The morphology of hippocampal abnormality found in these patients is quite different from that observed in hippocampal sclerosis.

\section{DISCUSSION}

Although temporal lobe abnormalities are frequently observed in patients with epilepsy, arachnoid cysts were rarely found among our patients. However, in the four patients with middle fossa arachnoid cysts, we found not only signs of temporal lobe hypogenesis, but also signs of hippocampal dysgenesis (bilateral in one of them).

Hippocampal dysgenesis is due to a malformation associated with abnormalities in the complex process of rotation and folding, which ends in abnormal shape, axis and internal structure ${ }^{8,9}$. Such findings have been reported in asymptomatic individuals from families with either febrile convulsions or temporal lobe epilepsy ${ }^{10,11}$. Recently, post-mortem pathological study of hippocampal malformation in an adult patient with temporal lobe epilepsy revealed abnormal position and complex convolutional malformations isolated to the hippocampal formation ${ }^{12}$. All these evidences point to an inherited abnormality in the mesial temporal region that is not necessarily associated with epilepsy.

Although temporal volume reduction can be found in patients with epilepsy and hippocampal abnormalities, the co-existence of arachnoid cysts indicates a malformative etiology. In the small number of patients with middle fossa arachnoid cysts identified in this study, the origin of the cyst can be attributed to temporal lobe hypogenesis.

\section{REFERENCES}

1. Garcia Santos JM, Martinez-Lage J, Gilabert Ubeda A, Capel Aleman A, Climent Oltra V. Arachnoid cysts of the middle cranial fossa: a consideration of their origins based on imaging. Neuroradiology 1993;35:355-358.

2. Wester K. Peculiarities of intracranial arachnoid cysts: location, sidedness, and sex distribution in 126 consecutive patients. Neurosurgery 1999;45:775-779.

3. Starkman SP, Brown TC, Linell SA. Cerebral arachnoid cysts. J Neuropathol Exp Neurol 1958;17:484-500.

4. Robinson RG. The temporal lobe agenesis syndrome. Brain 1964;88:87-106

5. Robertson SJ, Wolpert SM, Runge VM. MR imaging of middle cranial fossa arachnoid cysts: temporal lobe agenesis syndrome revisited. Am J Neuroradiol 1989;10:1007-1010.

6. Cendes F, Andermann F, Gloor P, et al. MRI volumetric measurements of amygdala and hippocampus in temporal lobe epilepsy. Neurology 1993;43:719-725.

7. Arroyo S, Santamaria J. What is the relationship between arachnoid cysts and seizure foci? Epilepsia 1997;38:1098-1102.

8. Duvernoy HM. The human hippocampus: an atlas of applied anatomy. München: J. F. Bergmann Verlag, 1988.

9. Baulac M, De Grissac N, Hasboun D et al. Hippocampal developmental changes in patients with partial epilepsy: magnetic resonance imaging and clinical aspects. Ann Neurol 1998;44:223-233.

10. Fernandez G, Effenberger O, Vinz B et al. Hippocampal malformation as a cause of familial febrile convulsions and hippocampal sclerosis. Neurology 1998;50:909-916.

11. Kobayashi E, Li M Li, Lopes-Cendes I, Cendes F. MRI evidence of hippocampal sclerosis in asymptomatic first degree relatives of patients with familial mesial temporal lobe epilepsy. Arch Neurol 2002 in press.

12. Thom M, Sisodiya SM, Lin WR et al. Bilateral isolated hippocampal malformation in temporal lobe epilepsy. Neurology 2002;58:1683-1686. 